\title{
Corrosion Inhibition of Carbon Steel by Anthraquinones Derivatives in 1.0 M HCl: Electrochemical and Quantum Calculations
}

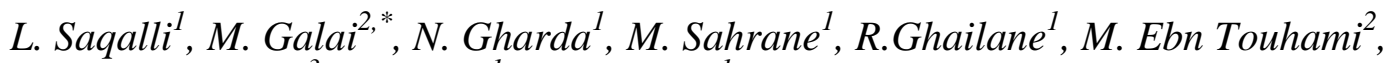 \\ Y. Peres-lucchese ${ }^{3}$, A. Souizi ${ }^{l}$, N. Habbadi ${ }^{1}$. \\ ${ }^{1}$ Laboratory of Organic, Organometallic and Theoretical chemistry, Faculty of Science, Ibn Tofail \\ University, PB 13314 000, Kénitra, Morocco. \\ ${ }^{2}$ Laboratory of Materials Engineering and Environment: Modeling and Application, Faculty of \\ Science, University Ibn Tofail BP. 133-14000, Kenitra, Morocco. \\ ${ }^{3}$ Laboratory of Chemical Engineering (Labége), BP 84234 Campus INP-ENSIACET, 4 allée Emile \\ Monso, 31432 Toulouse Cedex 4, France \\ "E-mail: galaimouhsine@gmail.com
}

doi: $10.20964 / 2018.05 .40$

Received: 23 November 2017 / Accepted: 8 February 2018 / Published: 10 April 2018

The effect of hydroxyl group number of some anthraquinon derivatives 1,2,4-trihydroxyanthraquinone (purpurin) and 1,4-dihydroxyanthraquinone (quinizarin) on their corrosion inhibition efficiency has been reported in order to establish a relationship between inhibitor efficiency and molecular structure. Experimental study is based on the potentiodynamic polarization curves and electrochemical impedance spectroscopy (EIS). On the other hand, the quantum chemistry calculations were performed using B3LYP/6-31G (d) method to determine the electronic and structural parameters of the studied anthraquinon derivatives. The results revealed that the compound containing supplementary group $(\mathrm{OH})$ presents the highest inhibition efficiency $(91.5 \%)$ in the case of Purpurin, that value is less than that obtained for Quinizarin $(89.0 \%)$. The experimental study indicated that the inhibition efficiency depends on concentration and molecular structure of the investigated compounds. The obtained experimental and theoretical results agree well and confirm that Purpurin, possessing the most number of $\mathrm{OH}$ group, is the better inhibitor.

Keywords1,2,4-trihydroxyanthraquinone, 1,4-dihydroxyanthraquinone, Corrosion inhibitor, EIS, Polarization curves, DFT

\section{$\underline{\text { FULL TEXT }}$}

(C) 2018 The Authors. Published by ESG (www.electrochemsci.org). This article is an open access article distributed under the terms and conditions of the Creative Commons Attribution license (http://creativecommons.org/licenses/by/4.0/). 